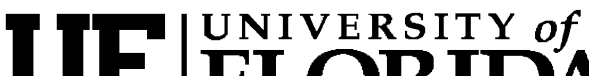 FLORIDA \\ IFAS Extension
}

\section{Bed Bugs and Blood-Sucking Conenose ${ }^{1}$}

\author{
P. G. Koehler, R. M. Pereira, M. Pfiester, and Jeff Hertz ${ }^{2}$
}

\section{Bed Bugs}

Bed bugs are blood-feeding insects (Figures 1-3) that feed mainly on the blood of humans, but also suck blood from other animals, such as birds, bats, and rodents. Bed bugs usually feed at night when people are asleep because the host is unaware that they are being fed upon. As bed bugs feed (Figure 3), they inject a salivary secretion into the wound to prevent coagulation. This fluid often causes the skin to itch and become swollen. Scratching causes sores which may become infected. Bed bugs are not known to transmit any human pathogens but can cause emotional distress to those affected.

When associated with humans, bed bugs generally infest dwellings such as houses, hotels, dormitories, and cruise ships, but have also been known to infest places such as subways, movie theaters, nursing homes, hospitals, and planes. During the day, bed bugs hide in cracks and crevices and can be found in wall outlets, behind baseboards, wallpaper and pictures, between bed joints and slats, along the seams of mattresses and in bed linens. The cryptic nature of bed bugs makes them difficult to detect and locate, making control a complex and laborious process that usually consists of an integrated approach that combines insecticides with other methods.

Bed bugs are transmitted from one place to another because they "hitchhike" on belongings, such as clothes, suitcases, second-hand beds, furniture, and bedding. Female bed bugs disperse more than any other stage, so it is likely that the bed bugs that "hitchhike" on peoples belongings are mostly females. Because female bed bugs can store male sperm for 4-6 weeks, it is also likely that they are pregnant. Therefore a single, pregnant female that is transferred to a different location can begin a new infestation. Severe bed bug infestations tend to have a sweetish, foul odor which is caused by an oily liquid they emit.

\section{Life Cycle}

The adult bed bug is about 1/4 inch long, flat, ovoid in shape, and has no wings. It is generally brown in color except after a blood meal. The body then becomes swollen and the color changes to dark red from the ingested blood. One female can produce a total of 200-500 eggs in her lifetime, laying anywhere from 10 to 50 eggs at a time. The eggs are

1. This document is ENY-227 (IG083), one of a series of the Entomology and Nematology Department, Florida Cooperative Extension Service, Institute of Food and Agricultural Sciences, University of Florida. First published: April 1993. Revised: November 2008. Please visit the EDIS Website at http://edis.ifas.ufl.edu.

2. P. G. Koehler, professor, extension entomologist R. M. Pereira, associate research scientist, M. Pfiester, graduate assistant entomologist, Entomology and Nematology Department, Cooperative Extension Service, Institute of Food and Agricultural Sciences, University of Florida, Gainesville, FL 32611 and J. Hertz, Navy entomologist.

The Institute of Food and Agricultural Sciences (IFAS) is an Equal Opportunity Institution authorized to provide research, educational information and other services only to individuals and institutions that function with non-discrimination with respect to race, creed, color, religion, age, disability, sex, sexual orientation, marital status, national origin, political opinions or affiliations. U.S. Department of Agriculture, Cooperative Extension Service, University of Florida, IFAS, Florida A. \& M. University Cooperative Extension Program, and Boards of County Commissioners Cooperating. Larry Arrington, Dean 


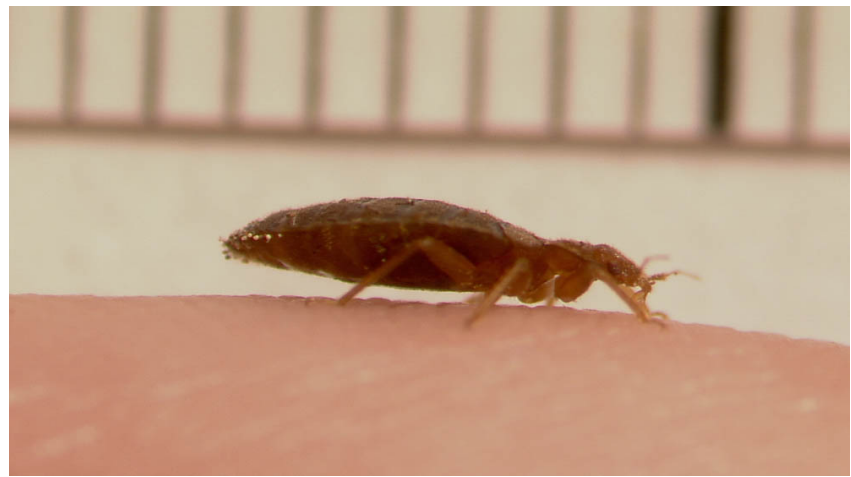

Figure 1. Adult. Credits: Joe Smith, University of Florida

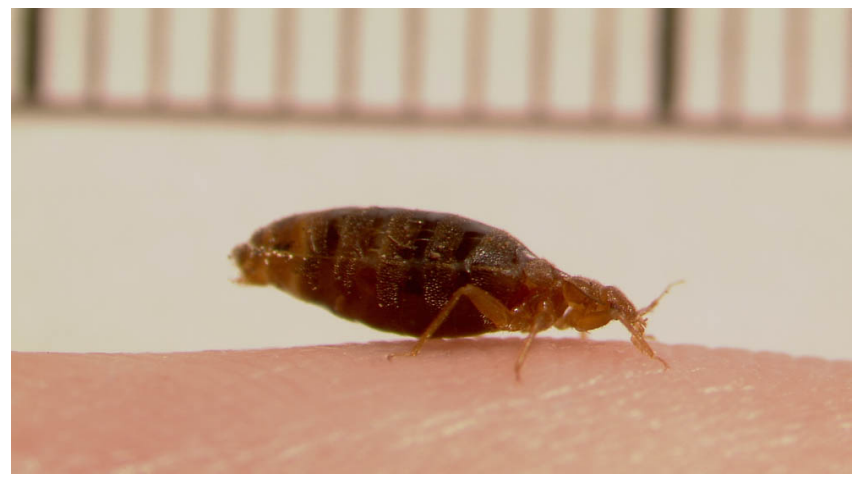

Figure 2. Engorged adult. Credits: Joe Smith, University of Florida

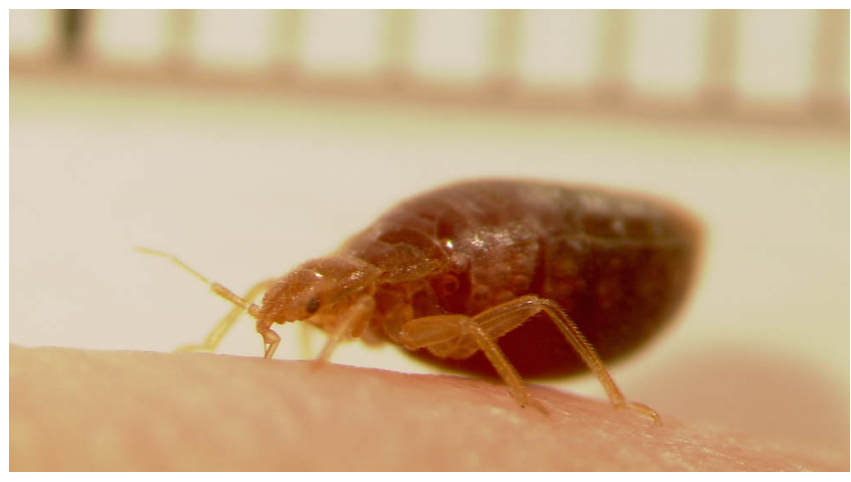

Figure 3. Feeding adult. Credits: Joe Smith, University of Florida

$1 / 25$ " long and are slightly curved. They are usually deposited in clusters and fastened to cracks and crevices or rough surfaces near adult harborages with a sticky cement-type substance.

The eggs hatch in one to three weeks. The newly hatched nymph is similar in shape to the adult but much smaller and straw colored before feeding. The newly hatched nymphs and eggs can be very difficult to see without the use of magnifying equipment. The newly hatched nymph turns red or purple in color after getting a blood meal (Figure 4). There are 5 nymphal stages for bed bugs to reach maturity, which usually take 35-48 days. Adult bed bugs can survive for 6-7 months without a blood meal and have been known to live in abandoned houses for 1 year. In some cases they survive without humans by attacking birds and rodents.

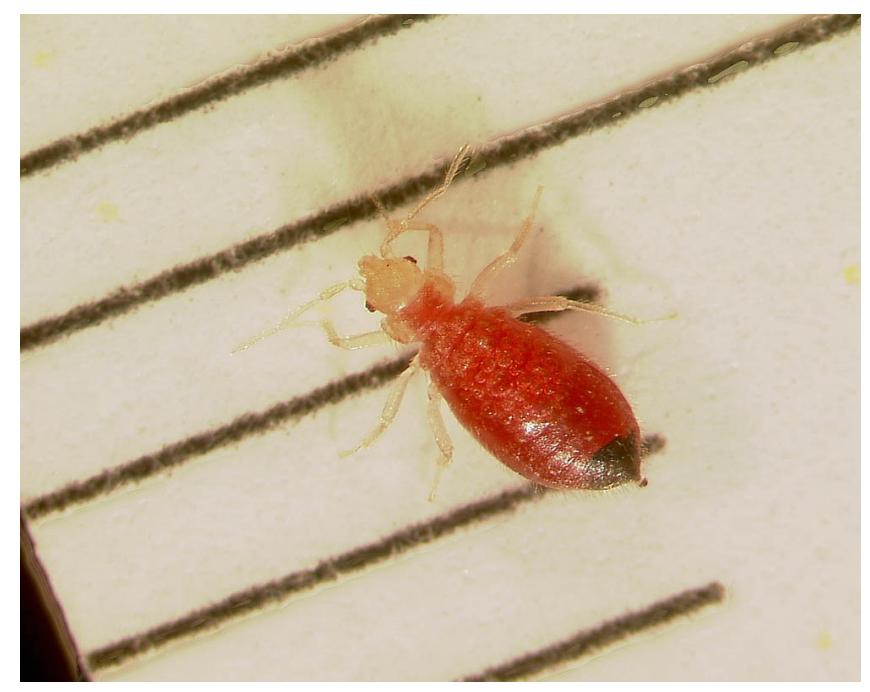

Figure 4. Engorged nymph. Credits: Joe Smith, University of Florida

\section{Detection}

Because there are so many possible harborages for bed bugs, detection of the pest can be difficult. It is especially difficult to locate small, early infestations of bed bugs because of their cryptic behavior. To complicate matters, many people have delayed reactions to bed bug bites and some people dont react to the bites at all, making it almost impossible to determine the specific timeframe a person was exposed to an infestation. These factors make it difficult to detect early infestations until the populations are excessive and overwhelming, but early detection makes control cheaper and more successful.

One successful method of detection is by the use of bed bug-detecting canines (Figure 5). They can be an essential tool for detection in places with a lot of rooms and a high turn-over, such as hotels, cruise ships, and dormitories. The ability to locate bed bug infestations before customer complaints can lower the possibility of litigations. Bed bug-detecting canines 
can also locate early infestations, even as few as one adult bed bug, leading to cheaper and more successful control.

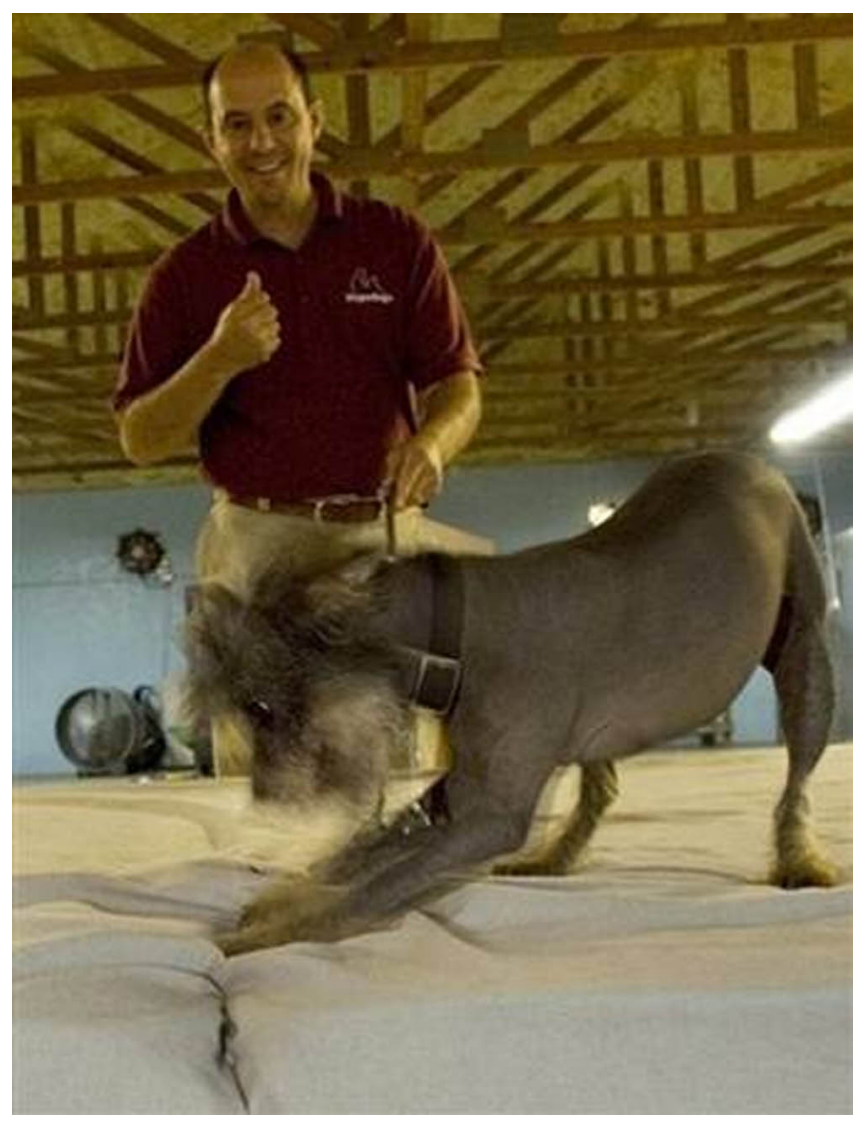

Figure 5. A bed bug-detecting canine indicating on a mattress that bed bugs are present.

Monitoring devices can also be used for detection of bed bugs. Sticky traps placed around beds and sofas can potentially confirm an infestation. There are also monitoring systems available that use carbon dioxide and heat as an attractant.

\section{Control}

Once bed bugs are found there are several methods that may be used to combat them, some old and some new (Table 1), although combining many methods usually yields the best result. No matter what methods are utilized by the pest control companies, there are many steps that can be taken by the home owners to optimize the possibility for success. First, as many bed bugs as possible should be physically removed from the premises. This is accomplished by vacuuming all of the carpets as well as visible bed bugs from the furniture. Once finished, ensure the vacuum bag is removed, sealed, placed in a zip lock bag, and placed in a deep freezer for at least a week. The four posts of the bed can then be placed in glass dishes. Bed bugs cannot climb smooth surfaces, so the glass dishes will exclude more bed bugs from being able to infest the bed, as long as the bed is away from the walls and covers are kept from touching the floor. All bedding should be laundered with soap and a borax additive and dried at a high temperature. Clothing, pillows, and drapery should be dry-cleaned. Also, contents inside dresser drawers should be emptied in order for insecticides to be sprayed under the drawers.

Insecticides: Insecticides are one option of control, but bed bugs can be extremely difficult to kill with insecticides. Unlike cockroaches (Figure 6), bed bugs do not have sticky pads on their tarsae (feet). When they crawl across residues of insecticide on surfaces, not much pesticide adheres to their bodies and, therefore, it does not kill them. In order to be effective, most insecticides must be applied directly to the insect. This requires searching for every bed bug in a room and spraying it directly. Remember, just because they are bed bugs, does not mean they cannot feed and live in other places, such as a couches or recliners. Of course, this process of finding the bug and spraying it is very labor intensive. Most pest control companies budget about five to ten hours to treat a typical bedroom. Because eggs are not affected by the spray, the treatment must be repeated after about two weeks to kill newly hatched nymphs.

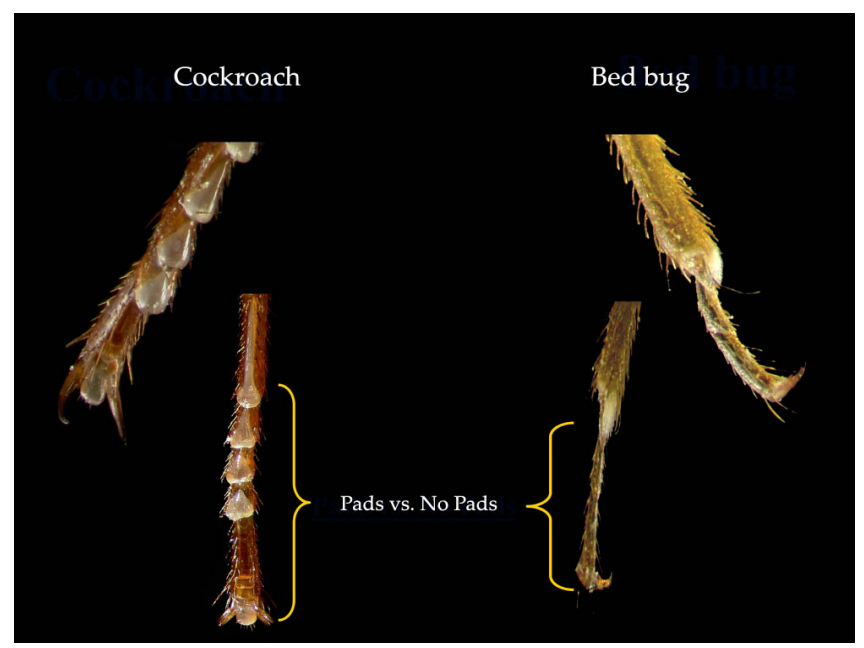

Figure 6. A comparison of cockroach tarsae and bed bug tarsae. 
Dust formulations provide more residual effectiveness than sprays because dusts are more easily transferred from surfaces than sprays. Therefore dust formulations are usually preferred over sprays for bed bug control. Insect growth regulators (IGRs) have also been tested for use on bed bugs but have yielded conflicting results in studies. A number of pesticides are available for use, as referenced by Table 2 . They should always be used in accordance with the manufacturers' labels. Insecticides can be classified by the mode of application: Mattress and Crack and Crevice, Indoor Surface, Indoor Space, and Fumigation. It is important to distinguish the differences between each category in order to provide the most effective treatment.

Mattress and Crack and Crevice: This application is for areas that are normally inconspicuous and difficult to reach. Pesticide dusts and some sprays fall into this category. Dust can be applied using either a puff duster or a paint brush. Dusts are lighter and can penetrate further than insecticide sprays; therefore, they should always be used in areas where there are deep cracks and crevices and behind electrical outlets. NEVER SPRAY INSECTICIDES DIRECTLY ON OR IN ELECTRICAL OUTLETS, AND NEVER SPRAY INSECTICIDES DIRECTLY ON MATTRESSES UNLESS THAT USE IS SPECIFIED ON THE LABEL! Remove outlet cover and apply dust into the wall void. Dusts are also preferred over sprays when treating the tufts, folds, and sleeping surfaces of mattresses.

Indoor Surface: This application is for areas where the bed bugs are likely to crawl in route to either their harborages or to where they feed. This type of application is often referred to as residual sprays. They are designed to remain active for an extended period of time to maximize the effectiveness of the application. These sprays should be applied to the bed frame and the non-sleeping surfaces of mattresses. Dresser drawers should be removed and turned upside down, ensuring all surfaces are sprayed. Spray baseboards and under the edge of carpet around the entire perimeter of the room.
Indoor Space: This application is used to kill exposed insects on contact. These insecticides are often in the form of aerosols. When harborages are found, spray the insecticide in the air in the vicinity toward the bed bugs. Aerosols are preferred when treating sensitive materials such as clothing or stuffed animals. Sensitive items can be placed into a plastic garbage bag or a closet (which is also likely to be infested). Spray aerosol into the closet or bag and seal for 10-15 minutes.

Fumigation: This is an application of lethal gas to an enclosed structure to eliminate pests. During fumigation, the building must be emptied of all inhabitants for a certain time period. Although it can be costly, fumigation kills every stage of bed bugs including eggs, and should be considered in severe infestations. If total building fumigation is not possible, containerized fumigation may be an option. This method involves the transfer of furniture and other items into a trailer truck or similar container, after which the container and its contents are fumigated. Other control methods are applied inside the building during the fumigation process. It is important to note that using fumigation alone leaves no residual and so cannot help prevent a reinfestation.

Resistance: Bed bugs are known to be resistant to many insecticides, especially pyrethroids. This means that some bed bug populations may not be killed with pyrethroid insecticides. This may be due to cross resistance to DDT. Bed bugs were first reported to be resistant to DDT in the 1950s. Research shows that the organophosphates and carbamates are still effective, but are not registered for use indoors.

Non-chemical control: These methods can include physical removal as discussed earlier, and sealing the mattress and box springs in mattress encasements to ensure any missed bed bugs do not attempt to reestablish themselves. The use of mattress encasements also makes bed bug inspections easier and eliminates the bed as a possible harborage site. If encasements are used, be sure to purchase brands that say they are "bite proof" as well as "escape proof." Another effective technique is exclusion by placing glass barriers around the bedposts and keeping the bed frame away from adjacent walls. 
Heat is a control method that has been utilized since the early 1900s. Bed bugs die at temperatures above $45^{\circ} \mathrm{C}$ which is about $113^{\circ} \mathrm{F}$. There are many pest control companies that offer some kind of heat treatment to kill bed bugs, and there are a variety of ways that it can be accomplished. One method is to build a box out of polystyrene sheathing board insulation around the furniture and other materials to be treated, and use oil-filled electrical space heaters inside the box to reach the necessary temperature. Another method is to use large commercial heaters to heat the entire room and its contents.

\section{Blood-Sucking Conenose}

The blood-sucking conenose (Figure 5), or "kissing bug", primarily feeds at night on the blood of sleeping people or animals, such as raccoons and opossums that burrow in the vicinity. Most bites from conenose bugs are rarely felt, however, some can be quite painful. Infection can occur if the bite wounds are scratched. It is a potential vector of Trypanosoma cruzi, which causes Chagas disease in Latin American countries.

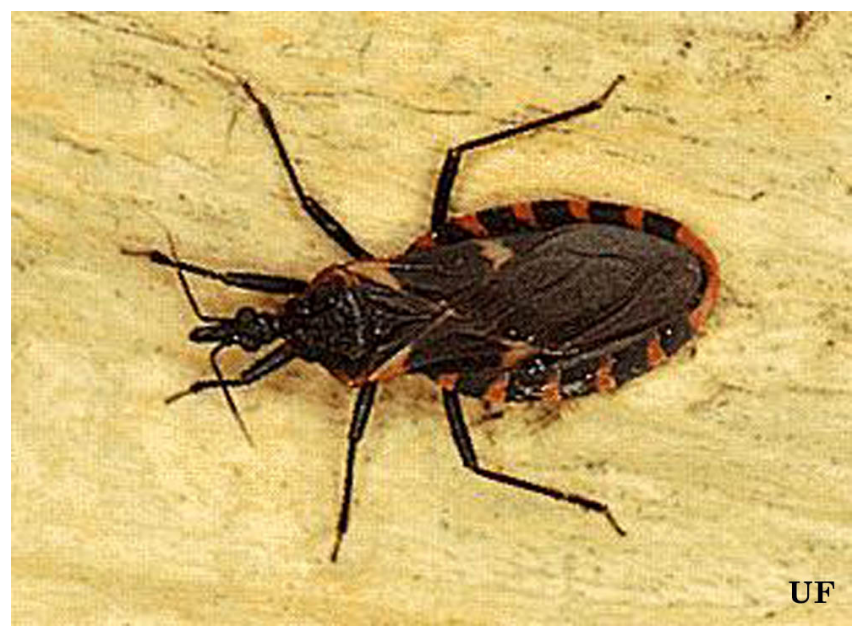

Figure 7. Blood-sucking conenose. Credits: James Castner, University of Florida

The blood-sucking conenose is a brown, winged bug, 3/4 inch long with the edges of its abdomen alternating in light and dark colors. They have a slender straight beak with piercing-sucking mouthparts. The antennae are inserted on the side of the head between the eyes and the end of the beak.

The blood-sucking conenose enters into a home by either crawling through cracks in the foundation, torn window screens, or other structural inadequacies; many times they enter by simply clinging to a domestic pet or to the clothing of an unaware person. Once indoors, they are found in bedding, cracks in the floors and walls or under furniture.

\section{Life Cycle}

The life cycle of the conenose varies considerably depending on temperature, humidity, and availability of hosts. Females lay one egg at a time, up to 5 eggs each day. A total of 200-300 eggs can be produced each year by one female. The females place the eggs in basements, attics, under baseboards, and other inconspicuous places. The eggs are $1.5 \mathrm{~mm}$ long, white and hatch in approximately 13-35 days. There are 8 nymphal instars before the conenose reaches maturity. The adults can live from 6 months to 3 years.

\section{Control}

To control the blood-sucking conenose bug you must first locate where they are living and trace where they are entering into the home or structure. Inspect all point of entry locations for cracks or tears and check attics and crawlspaces for harborages. Once they are found there are several different methods in combating them.

A non-chemical approach is by exclusion. Repair any damaged entry points to the home such as screens and foundation cracks. Reinforce caulking around windows and other cracks and crevices. Eliminate animal harborages and increase the distance of farm and domestic animal cages from the home.

While these bugs can be difficult to manage, a thorough crack and crevice application of an approved pesticide can control them. Unfortunately, because they are rare pests, most labels will not list them as a target pest. You may still use most of the common crack and crevice or indoor surface insecticides as long as the manufacturer's label does not forbid its use against pests not listed, the site of application is listed on the manufacturer's label, and the insecticide is not applied in a method prohibited by the manufacturers label. 
Crack and Crevice: application is for areas that are normally inconspicuous and difficult to reach. Pesticide dusts and some sprays fall into this category. Dust can be applied using either a puff duster or a paint brush. Dusts are lighter and can penetrate further than pesticide sprays; therefore, they should always be used in areas where there are deep cracks and crevices and behind electrical outlets. NEVER SPRAY INSECTICIDE DIRECTLY ON OR IN ELECTRICAL OUTLETS! Remove outlet cover and apply dust into the wall void.

Indoor Surface: application is for areas where the conenose bugs are likely to crawl in route to either their harborages or to where they feed. This type of application is often referred to as residual sprays. They are designed to remain active for an extended period of time to maximize the effectiveness of the application. Spray woodwork and all walls at least 2 feet above the floor for the entire perimeter of the room.

Table 1. New Techniques in Bed Bug Control

\begin{tabular}{|c|c|}
\hline Heat & Temperatures above $113-115^{\circ} \mathrm{F}$ kill all bed bug stages. \\
\hline Whole-room or whole-house & Energy requirements are high and special equipment is needed. \\
\hline Room contents only & $\begin{array}{l}\text { Furniture and other room contents can be contained within a styrofoam box and } \\
\text { heated with household oil-filled heaters to } 113-115^{\circ} \mathrm{F} \text { while the room is treated } \\
\text { with residual pesticides. }\end{array}$ \\
\hline Containerized & $\begin{array}{l}\text { Furniture and other infested materials can be placed in an insulated container, } \\
\text { which is heated }>\text { to } 113-115^{\circ} \mathrm{F} \text {. }\end{array}$ \\
\hline Clothes Dryer & $\begin{array}{l}\text { Clothes, bedding materials, and other infested materials can be heated in dryer to } \\
\text { kill bed bugs. Because of the high temperature that can be reached, a few minutes } \\
\text { of treatment are sufficient eliminate infestations. }\end{array}$ \\
\hline Steaming & $\begin{array}{l}\text { High temperature steam kill bed bugs immediately without leaving pesticide } \\
\text { residues. This treatment is ideal for mattresses and other surfaces with high } \\
\text { contact with human skin or crevices hard to treat with other methods. }\end{array}$ \\
\hline Fumigation & Toxic gases (e.g., sulfuryl fluoride) kill all bed bug stages. \\
\hline Structure & $\begin{array}{l}\text { The structure is tarped to contain the fumigant for a period of time needed to } \\
\text { provide adequate lethal cumulative dose of the toxic gas. }\end{array}$ \\
\hline Containerized & $\begin{array}{l}\text { Furniture and other infested materials can be placed in a sealed container, which } \\
\text { is injected with fumigant. }\end{array}$ \\
\hline $\begin{array}{l}\text { Mattress and pillow } \\
\text { encasements }\end{array}$ & $\begin{array}{l}\text { Specially designed encasements can prevent bed bugs from getting established } \\
\text { in mattresses and box springs, or preventing established populations from leaving } \\
\text { these areas to feed on blood. }\end{array}$ \\
\hline Diatomaceous earth / Silica gel & $\begin{array}{l}\text { Dust products formulated with these dehydrating and abrasive powders (e.g., in } \\
\left.\text { Tri-Die }{ }^{T M}\right) \text { provide long-lasting residual protection against bed bug reinfestation of } \\
\text { harborages. }\end{array}$ \\
\hline Traps & $\begin{array}{l}\text { Because bed bugs are attracted to heat, } \mathrm{CO}_{2} \text {, and certain host odors, traps have } \\
\text { been developed to monitor presence of bed bugs. Some traps may be adequate } \\
\text { for elimination of infestations. }\end{array}$ \\
\hline
\end{tabular}


Table 1. New Techniques in Bed Bug Control

\begin{tabular}{|l|l||}
\hline \hline Bed bug-detecting dogs & $\begin{array}{l}\text { Specially trained dogs can detected small, hidden bed bug infestations with > 95\% } \\
\text { accuracy. A well trained dog will detect only live insects and eggs, and will ignore } \\
\text { dead bed bugs, bed bug debris, and other structure-infesting insects. }\end{array}$ \\
\hline \hline
\end{tabular}

Table 2. Some insecticides labeled for bed bug control.

\begin{tabular}{|c|c|c|}
\hline & Trade name & Active ingredient \\
\hline \multirow[t]{5}{*}{ Mattress and crack and crevice } & & \\
\hline & Suspend & deltamethrin \\
\hline & Delta Dust & deltamethrin \\
\hline & Bedlam, SteriFab & d-phenothrin \\
\hline & $\mathrm{DE}$ & diatomaceous earth \\
\hline \multirow[t]{3}{*}{$\begin{array}{l}\text { Residual sprays } \\
\text { * NO MATTRESS TREATMENT* }\end{array}$} & & \\
\hline & Talstar & bifenthrin \\
\hline & Onslaught & fenvalerate \\
\hline \multirow{4}{*}{ Indoor spaces } & ULD BP-300 or BP-50 & synergized pyrethrins \\
\hline & Pyrenone 50 & synergized pyrethrins \\
\hline & Tempo & cyfluthrin \\
\hline & Suspend & deltamethrin \\
\hline \multirow[t]{2}{*}{ Fumigation } & & \\
\hline & Vikane & sulfuryl fluoride \\
\hline \multirow[t]{3}{*}{ Insect Growth Regulators } & & \\
\hline & Gentrol & hydroprene \\
\hline & ULD Hydropy-300 & hydroprene \\
\hline
\end{tabular}

